\title{
Phylogenetic Origin of Human Chromosomes 7, 16 , and 19 and their Homologs in Placental Mammals
}

\author{
Florence Richard, ${ }^{1,2,4}$ Martine Lombard, ${ }^{1}$ and Bernard Dutrillaux ${ }^{1,3}$ \\ ${ }^{1}$ Unité Mixte de Recherche (UMR) 147 Centre National de Recherche Scientifique (CNRS), Institut Curie, Section Recherche, \\ 75248 Paris Cedex 05, France; ${ }^{2}$ Université de Versailles-Saint-Quentin, Versailles, France; $78030{ }^{3}$ Département de \\ Radiobiologie, CEA-DSV, 92265 Fontenay-aux-Roses, France
}

\begin{abstract}
The origin of human chromosomes (HSA) 7, 16, and 19 was studied by comparing data obtained from chromosome banding, chromosome painting, and gene mapping in species belonging to 11 orders of placental mammals (Eutherians). This allowed us to propose the reconstruction of their presumed ancestral forms. The HSA7 homologs were composed of two parts, the largest forming an acrocentric. The smallest formed one arm of a small submetacentric; the other arm was composed of sequences homologous to the short arm of HSAl6 (HSA16p). The sequences homologous to the long arm of HSAl6 (HSA16q) were associated with sequences homologous to the long arm of HSA19 (HSA19q) and formed another submetacentric. From their origin, these chromosomes underwent the following rearrangements to give rise to current human chromosomes: centromeric fission of the two submetacentrics in ancestors of all primates ( 80 million years ago); fusion of the HSA19p and HSA19q sequences, originating the current HSA19, in ancestors of all simians ( $~ 55$ million years ago); fusions of the HSA16p and HSA16q sequences, originating the current HSA16 and the two components of HSA7 before the separation of Cercopithecoids and Hominoids ( $\sim 35$ million years ago); and finally, pericentric and paracentric inversions of the homologs to HSA7 after the divergence of orangutan and gorilla, respectively. Thus, compared with HSA16 and HSA19, HSA7 is a fairly recent chromosome shared by man and chimpanzee only.
\end{abstract}

According to paleontological data, eutherian or placental mammals diverged some 130 million years ago from marsupial mammals. Because the reconstruction of their phylogenetic relationships using fossil records is not easy, genetic data are greatly needed (Novacek 1992). Chromosome comparisons were developed to compare closely related and progressively more and more distant species. Chromosome banding comparisons were even used to compare species belonging to different orders of placental mammals (Dutrillaux et al. 1980; Dutrillaux and Couturier 1983; Petit et al. 1984), revealing a high conservation of many large chromosomal segments. Starting from human chromosomes, this allowed the reconstruction of ancestral karyotypes, assuming that chromosomes with similar banding patterns shared by species from different genera, families, or even orders were already present in their common ancestors (Dutrillaux et al. 1982; Dutrillaux and Couturier 1983). The efficiency of chromosome banding comparisons is however limited: When distant species are considered, they do not allow accurate comparisons of small chromosomes or chromosomal segments. In situ hybridization techniques, using whole chromosome probes on metaphases from various species (Zoo-FISH) proved to be a good comple-

${ }^{4}$ Corresponding author.

E-MAIL florence.richard@curie.fr; FAX 33.1.42.34.66.74. ment, especially for the comparison of these small chromosomal segments. These methods are also particularly adapted to study taxa with highly rearranged chromosomes, such as gibbons (Jauch et al. 1992; Koehler et al. 1995; Müller et al. 1998) and Muridae (Scalzi and Hozier 1998; Guilly et al. 1999), for which chromosome banding failed to propose complete comparisons. They also confirmed the proposed analogies between man and great apes (Dutrillaux 1975; Jauch et al. 1992), man and macaques (Muleris et al. 1984; Wienberg et al. 1992), and man and lemurs (Apiou et al. 1996; Müller et al. 1997). These improvements make it now possible to accurately compare man and nonprimate mammals (Hayes 1995; Rettenberger et al. 1995; Frönicke et al. 1996, 1997; Raudsepp et al. 1996; Hameister et al. 1997; Wienberg et al. 1997; Bielec et al. 1998; Dixkens et al. 1998; Nash et al. 1998; Volleth et al. 1999) and reconstruct the origin of human and other primate chromosomes from their common eutherian ancestors.

The study was mainly focused on the origin of human chromosome 7 (HSA7) in placental mammals. Because sequences homologous to segments of HSA7 were found recurrently located on the same chromosomes as those of HSA16 and HSA19, the study was extended to these two chromosomes. The reconstruction of the evolution of HSA7 was already proposed after chromosome banding comparisons in primates 
(Dutrillaux 1979a). It was concluded that the ancestral form of HSA7 was composed of two acrocentrics: one large and one small, RT-band rich. The large acrocentric was also found in carnivore (Dutrillaux and Couturier 1983) and rodent (Petit et al. 1984) species, but the presumed small acrocentric could not be tracked. The identification of the homologs to HSA16 and HSA19 remained uncertain in nonprimate mammals. We considered our Zoo-FISH results on species belonging to Carnivora (lion), Edentata (armadillo), Lagomorpha (rabbit), Perissodactyla (zebra), primates (several species), Rodentia (squirrel), and Scandentia (tree shrew), and published data for species belonging to other orders. We propose a shared evolutive history for the homologs to HSA7, HSA16, and HSA19 before their emergence as individual chromosomes in primate ancestors and describe the alterations that occurred during the evolution of these chromosomes for a period of about 80 million years. These Zoo-FISH are compared with banding and gene mapping data.

\section{RESULTS AND DISCUSSION}

Successful paintings were obtained for the following species: (1) HSA7 probe: all of the studied species; (2)

Table 1. Information about Mammalian Species Considered in this Study (Bold) and Literature

\begin{tabular}{|c|c|c|c|}
\hline Orders and families & Latin names & $\begin{array}{l}\text { Used } \\
\text { codes }\end{array}$ & English names \\
\hline Artiodactyla & $\begin{array}{l}\text { Bos taurus } \\
\text { Muntiacus crinifrons } \\
\text { Muntiacus muntjak } \\
\text { Ovis aries } \\
\text { Sus scrofa }\end{array}$ & BTA & $\begin{array}{l}\text { cattle } \\
\text { black muntjac deer } \\
\text { Indian muntjac deer } \\
\text { sheep } \\
\text { pig }\end{array}$ \\
\hline Carnivora & $\begin{array}{l}\text { Ailuropoda melanoleuca } \\
\text { Felis cattus } \\
\text { Mustela vison } \\
\text { Panthera leo } \\
\text { Phoca vitulina }\end{array}$ & $\begin{array}{l}\text { FCA } \\
\text { MVI } \\
\text { PLE } \\
\text { PVI }\end{array}$ & $\begin{array}{l}\text { giant panda } \\
\text { cat } \\
\text { American mink } \\
\text { lion } \\
\text { harbor seal }\end{array}$ \\
\hline Cetacea & Tursiops truncatus & TTR & Atlantic bottlenose dolphin \\
\hline Chiroptera & Glossophaga soricina & GSO & long-tongued bat \\
\hline Edentata & Dasypus novemcinctus & DNO & nine-banded armadillo \\
\hline Insectivora & Sorex araneus & SAR & common shrew \\
\hline Lagomorpha & Oryctolagus cuniculus & $\mathrm{OCU}$ & Old World rabbit \\
\hline Perissodactyla & $\begin{array}{l}\text { Equus caballus } \\
\text { Equus zebra }\end{array}$ & $\begin{array}{l}\mathrm{ECA} \\
\mathrm{EZA}\end{array}$ & $\begin{array}{l}\text { horse } \\
\text { mountain zebra }\end{array}$ \\
\hline $\begin{array}{l}\text { Primates } \\
\quad \text { Pongidae (great apes) }\end{array}$ & $\begin{array}{l}\text { Homo sapiens } \\
\text { Pan paniscus } \\
\text { Pan troglodytes } \\
\text { Gorilla gorilla } \\
\text { Pongo pygmaeus }\end{array}$ & $\begin{array}{l}\text { HSA } \\
\text { PPA } \\
\text { PTR } \\
\text { GGO } \\
\text { PPY }\end{array}$ & $\begin{array}{l}\text { man } \\
\text { bonobo } \\
\text { chimpanzee } \\
\text { gorilla } \\
\text { orangutan }\end{array}$ \\
\hline Hylobatidae (gibbons) & $\begin{array}{l}\text { Hylobates lar } \\
\text { Hylobates Nomascus concolor } \\
\text { Hylobates syndactylus }\end{array}$ & $\begin{array}{l}\text { HLA } \\
\text { HNC } \\
\text { HSY }\end{array}$ & $\begin{array}{l}\text { white-handed gibbon } \\
\text { concolor gibbon } \\
\text { siamang }\end{array}$ \\
\hline $\begin{array}{l}\text { Cercopithecoidae } \\
\text { (Old World monkeys) }\end{array}$ & $\begin{array}{l}\text { Cercopithecus aethiops } \\
\text { Cercopithecus diana } \\
\text { Cercopithecus mitis } \\
\text { Colobus abyssinicus } \\
\text { Macaca sp. } \\
\text { Papio sp. } \\
\text { Presbytis cristatus }\end{array}$ & $\begin{array}{l}\text { CAE } \\
\text { CDI } \\
\text { CMI } \\
\text { CAB } \\
\text { MAC } \\
\text { PAP } \\
\text { PCR }\end{array}$ & $\begin{array}{l}\text { grass monkey } \\
\text { Diana monkey } \\
\text { diademed guenon } \\
\text { Northern black-and-white colobus } \\
\text { macaques } \\
\text { baboons } \\
\text { silvered leaf monkey }\end{array}$ \\
\hline $\begin{array}{l}\text { Cebidae } \\
\text { (New World monkeys) }\end{array}$ & $\begin{array}{l}\text { Alouatta seniculus } \\
\text { Ateles geoffroyi } \\
\text { Cebus capucinus } \\
\text { Pithecia pithecia }\end{array}$ & $\begin{array}{l}\text { ASE } \\
\text { AGE } \\
\text { CCA } \\
\text { PPI }\end{array}$ & $\begin{array}{l}\text { red howler monkey } \\
\text { black-handed spider monkey } \\
\text { white-throated capuchin } \\
\text { white-headed saki }\end{array}$ \\
\hline $\begin{array}{l}\text { Callitrichidae } \\
\text { (New World monkeys) }\end{array}$ & $\begin{array}{l}\text { Callimico goëldi } \\
\text { Callithrix jacchus } \\
\text { Saguinus fuscicollis }\end{array}$ & $\begin{array}{l}\text { CGO } \\
\text { CJA } \\
\text { SFU }\end{array}$ & $\begin{array}{l}\text { Goeldi's monkey } \\
\text { marmoset } \\
\text { brown-headed Tamarin }\end{array}$ \\
\hline Lemuridae (Prosimians) & $\begin{array}{l}\text { Eulemur fulvus } \\
\text { Eulemur macaco }\end{array}$ & $\begin{array}{l}\text { EFU } \\
\text { EMA }\end{array}$ & $\begin{array}{l}\text { brown lemur } \\
\text { black lemur }\end{array}$ \\
\hline Rodentia & Menetes berdmorei & MBE & Indochinese ground squirrel \\
\hline Scandentia & Tupaia chinensis & $\mathrm{TCH}$ & Chinese tree shrew \\
\hline
\end{tabular}




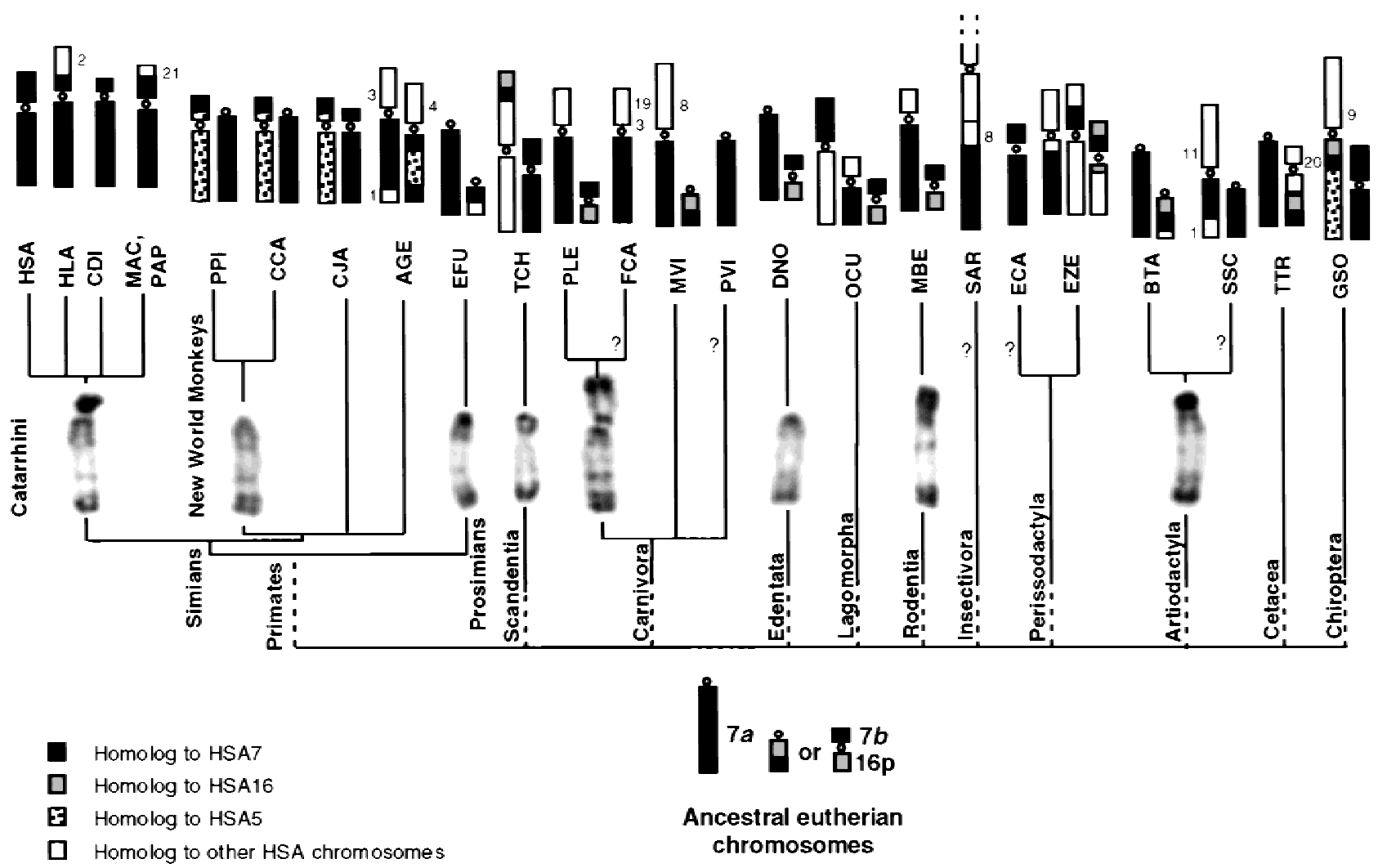

Figure 1 Reconstruction of the presumed ancestral chromosomes homologous to HSA7 (bottom) in placental mammals and their present status in living species (top). The two fragments of HSA7 observed in many species are indicated as $7 a$ and $7 b$. Expected but not observed syntenies $7 b-16 p$ by Zoo-FISH are indicated by a question mark. (See Table 1 for the three-letter code meaning.)

HSA16 probe: marmoset, white-throated capuchin and brown lemur; Chinese tree shrew; lion; nine-banded armadillo; Old World rabbit; Indochinese ground squirrel, and mountain zebra; (3) HSA19 probe: whitethroated capuchin, Chinese tree shrew, and mountain zebra.

For all species considered, Latin and common English names are given in Table 1 , with indications of the orders or families to which they belong.

\section{Evolution of HSA7 Homologs}

By combining our Zoo-FISH and chromosome banding data, it appeared that, except for Catarrhines (Old World monkeys, great apes, and man), homologous sequences to HSA7 were present in at least two chromosomes, in all the species studied (Fig. 1, see also Fig. 3 , below) These two chromosomes exhibited a similar banding pattern in different species belonging to different orders.

A large acrocentric homologous to a HSA7 fragment $(7 a)$ was observed in various species of primates (white-headed saki, white-throated capuchin, brown lemur) and in the nine-banded armadillo (Fig. 1). In other species, it constituted the whole arm of a metaor submetacentric chromosome, as in the lion and the
Indochinese ground squirrel. The marmoset and the Chinese tree shrew possessed different submetacentrics homologous to $7 a$ (Fig. 2a). More complex situations were observed for the Old World rabbit and the mountain zebra, in which fragments of $7 a$ were associated with chromosome fragments of different origin (Fig. $2 b)$. Because a large acrocentric or a whole chromosome arm with an identical banding pattern was observed in species belonging to several orders, we concluded, using the method of parsimony, that this chromosome was the ancestral form for many, if not all, placental mammals. No synteny (colocalization on a same chromosome) with other HSA chromosome segments was shared by different orders of mammals. In this hypothesis, the ancestral acrocentric would have undergone Robertsonian translocations in lion and squirrel, independent pericentric inversions in marmoset and tree shrew, or reciprocal translocations in rabbit and zebra lineages.

The small-sized chromosome segment homologous to HSA7 sequences $(7 b)$ and sequences homologous to HSA16 were syntenic in at least one species belonging to all eutherian orders we studied except for primates. No additional synteny was detected in the lion, the nine-banded armadillo, the Old World rabbit 

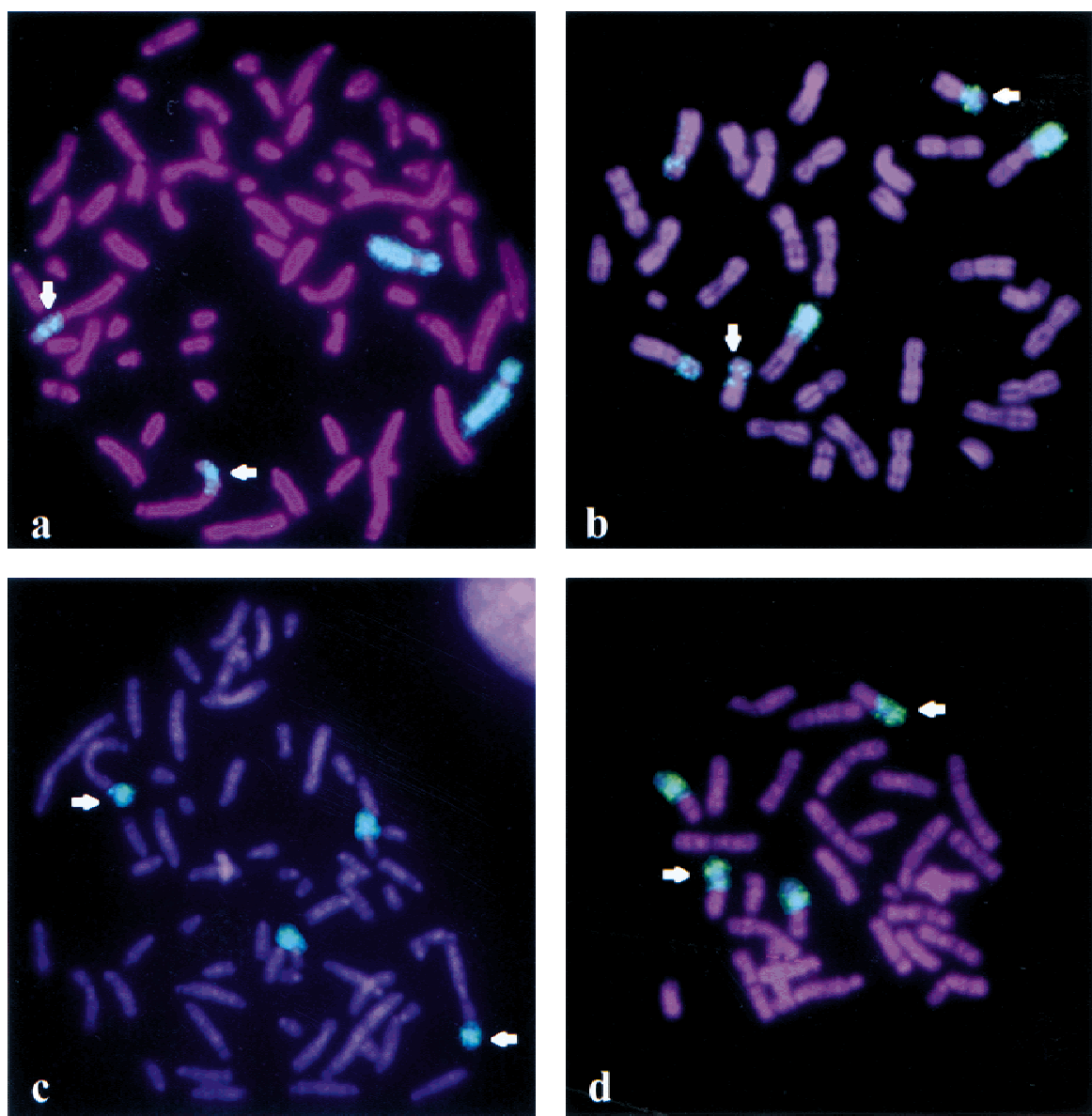

Figure 2 Chromosome paintings exhibiting homologies with human chromosomes $7(a, b)$ and $16(c, d)$ in the Chinese tree shrew $(a, c)$ and the mountain zebra $(b, d)$. Chromosomes were counterstained with DAPI and identified by reverse DAPI staining (not shown). Arrows indicate chromosomes hybridizing with both HSA7 and HSA16 probes.

and the Indochinese ground squirrel, whereas the $7 b+$ HSA16 synteny was found associated with other chromosomal material in the Chinese tree shrew and the mountain zebra (Figs. 1 and $2 \mathrm{c}, \mathrm{d}$ ). This link between $7 b+$ HSA16 fragments was described for cattle (Hayes 1995) and sheep (Burkin et al. 1997), as well as lemur (Müller et al. 1997), mink (Hameister et al. 1997), muntjac (Burkin et al. 1997; Yang et al. 1997), dolphin (Bielec et al. 1998), and bat (Volleth et al. 1999) species. Additional chromosome materials were found associated with the $7 b+$ HSA16 syntenic fragments in some taxa: HSA20 in the dolphin, HSA5 and HSA9 in the bat, and nonidentified sequences in cattle. The most parsimonious hypothesis is that $7 b+\mathrm{HSA} 16$ sequences formed a small ancestral chromosome that remained free in some taxa and underwent different translocations in others. When chromosome banding was considered, the HSA16 homologous sequences seemed to belong to the short rather than to the long arm of HSA16, in agreement with comparative gene mapping data from pig, cattle, sheep, and mink
(BOVMAP, http://locus.jouy. inra.fr/cgi-bin/bovmap/intro. pl, August 1999; Mouse Genome Database (MGD), http:// www.informatics.jax.org/, June 1999; Pigmap, http://www.toulouse.inra.fr/lgc/lgc.html, August 1999). The ancestral morphology of this small chromosome remains uncertain. That a small, apparently identical, submetacentric was observed in species from four orders (Carnivora, Edentata, Lagomorpha, and Rodentia, Fig. 3) suggests that this chromosomal form was ancestral. This interpretation is compatible with the other forms of the $7 b+$ HSA16 $\mathrm{p}$ fragment when it is translocated onto other chromosomes, as in the tree shrew, the zebra, and cattle among others. However, that the $7 b+$ HSA16p ancestral chromosome was acrocentric cannot be completely ruled out. Consequently, the fission that has originated the chromosome homologous to HSA16p in primates either occurred at the centromere position if the ancestral chromosome was submetacentric, or in intercallary position if it was acrocentric (Fig. 3).

Among primates, $7 b$ was found syntenic with HSA5 sequences in New World monkeys, with other sequences in lemurs and with $7 a$ in Catarrhines (Fig. 1). So, the most parsimonious interpretation is that a small acrocentric formed by $7 b$ sequences was ancestral for all primates. It underwent various translocations in Prosimians and New World monkeys and a Robertsonian translocation with $7 a$ leading to a submetacentric with a short arm very rich in R-bands in Old World monkeys.

In conclusion, in the common ancestor of placental mammals, it is most probable that sequences homologous to HSA7 formed a large acrocentric ( $7 a)$ and the short arm $(7 b)$ of a small submetacentric.

\section{Evolution of HSA16 Homologs}

HSA16 homologous sequences were found to be located on two different chromosomes in species belonging to the eleven orders studied (Fig. 3). One of the two parts of HSA16 sequences was recurrently syntenic with $7 b$ fragment. It corresponds to HSA16p, as suggested by chromosome banding and demonstrated by 


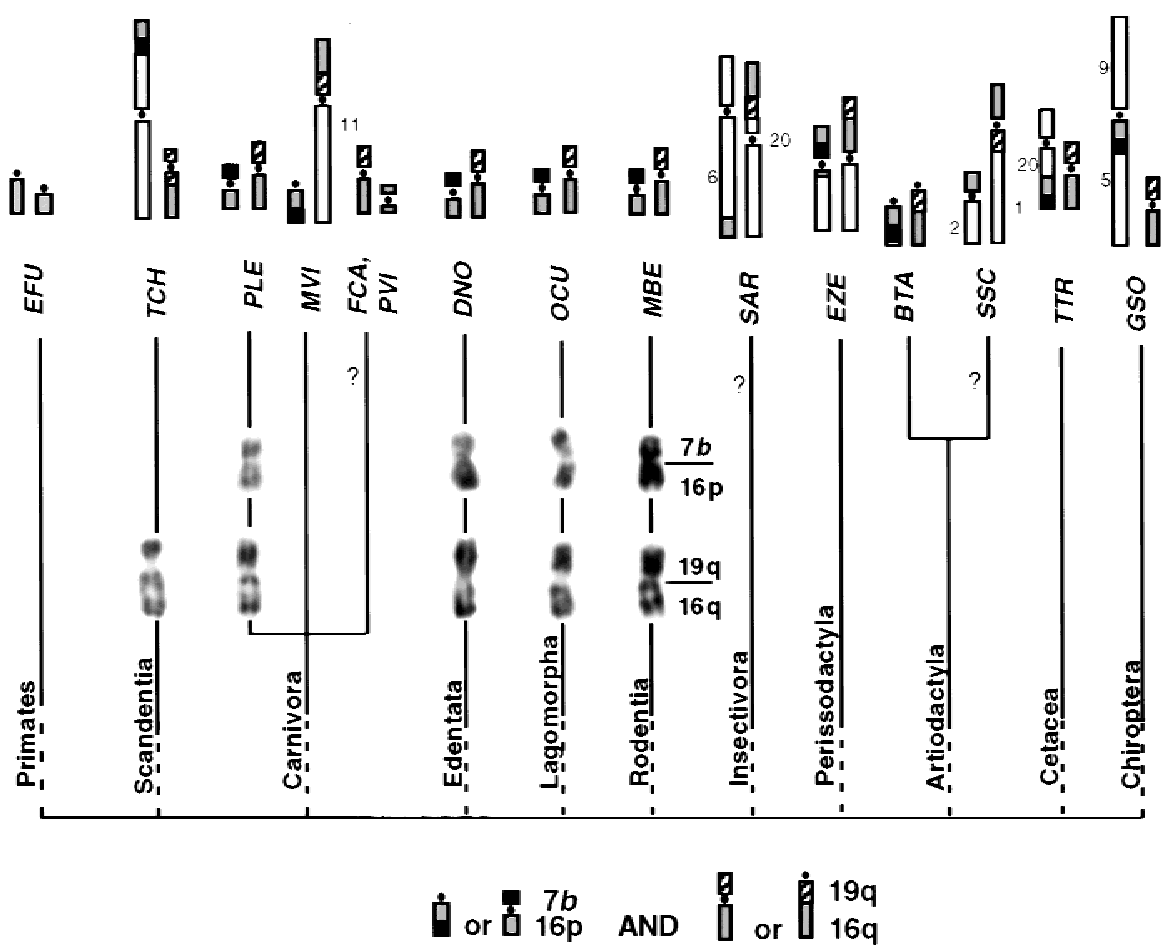

- Homolog to HSA7 (7b)

口 Homolog to HSA16

G Homolog to HSA19

\section{Ancestral eutherian chromosomes}

Figure 3 Reconstruction of the presumed ancestral chromosomes homologous to HSA16 (bottom) in placental mammals, their present status in living species (top), and their syntenies with HSA7 and HSA19 sequences. Expected but not observed syntenies $7 b-16 p$ by Zoo-FISH are indicated by a question mark. (See Table 1 for the three-letter code meaning.)
C Homolog to other HSA chromosomes

Evolution of HSA7, HSA16, and HSA19 Homologs in Primates

The reconstruction of HSA7, HSA16, and HSA19 evolution did not allow us to propose any branching among the various orders of placental mammals studied, as no derived rearrangement was shared by species belonging to two or more orders. Compared with presumed ancestral eutherian chromosomes, derived conditions were observed in primates, which allowed us to reconstruct a tree deduced from the method of parsimony (Fig. 4). Ancestral conditions could be proposed for the homologs to HSA7, HSA16, and HSA19 at different branchings of this tree. In all primates studied, neither the $7 b-$ HSA $16 \mathrm{p}$ nor the HSA16qHSA19q ancestral synteny was detected. Thus, both syntenies were disrupted, probably by fissions that occurred at the centromeric region of each presumed ancestral submetacentric. This clearly separates primate ancestors from all other orders.

gene mapping data. It forms the long arm of a small submetacentric, as described above.

Considering the rest of HSA16, a synteny between sequences homologous to HSA16 and HSA19 was observed in many species. It was first detected in the Old World rabbit by high-resolution chromosome banding (Dutrillaux et al. 1980). It forms a small submetacentric, very similar to chromosome 14 and 15 of the Indochinese ground squirrel and the lion, respectively, and slightly different than chromosome 20 of the nine-banded armadillo (this study). The existence of the synteny HSA16q-HSA19q was confirmed by different approaches in several taxa (for review, see Chowdhary et al. 1998). As it is also observed by ZooFISH in the Chinese tree shrew and the mountain zebra (this study), it exists in 10 different orders (Fig. 3). Considering the various combinations of HSA16q and HSA19q chromosome segments (Fig. 3), the most parsimonious interpretation is that the ancestral form was a submetacentric, still present in species belonging to six orders. Its short and long arms would be formed by sequences homologous to HSA19q and HSA16q, respectively.
In lemurs, the two acrocentrics $7 a$ and $7 b$ either remained free as in the brown lemur or underwent translocations as did $7 a$ in the black lemur (Müller et al. 1997). The ancestral acrocentric homologous to HSA19q and a part of HSA4 underwent a translocation specific to lemurs. Another translocation involving HSA16q homolog occurred in the black lemur, forming a HSA14-HSA15-HSA19p-HSA16q synteny. This synteny is a derived condition.

In all Simians studied, the synteny HSA19pHSA19q was observed, although further rearrangements have occurred in few taxa with highly rearranged karyotypes such as gibbons (Jauch et al. 1992; Koehler et al. 1995; Müller et al. 1998). Because the syntenic sequences form a small metacentric in many species as in man, this chromosome could be considered as the simian ancestral one. It has remained fairly stable because it was formed before New World and Old World monkeys divergence.

In all New World monkeys studied, an HSA10HSA16p synteny exists. The ancestral form is a submetacentric with a short arm homologous to HSA16p and a long arm homologous to HSA10q (Dutrillaux 


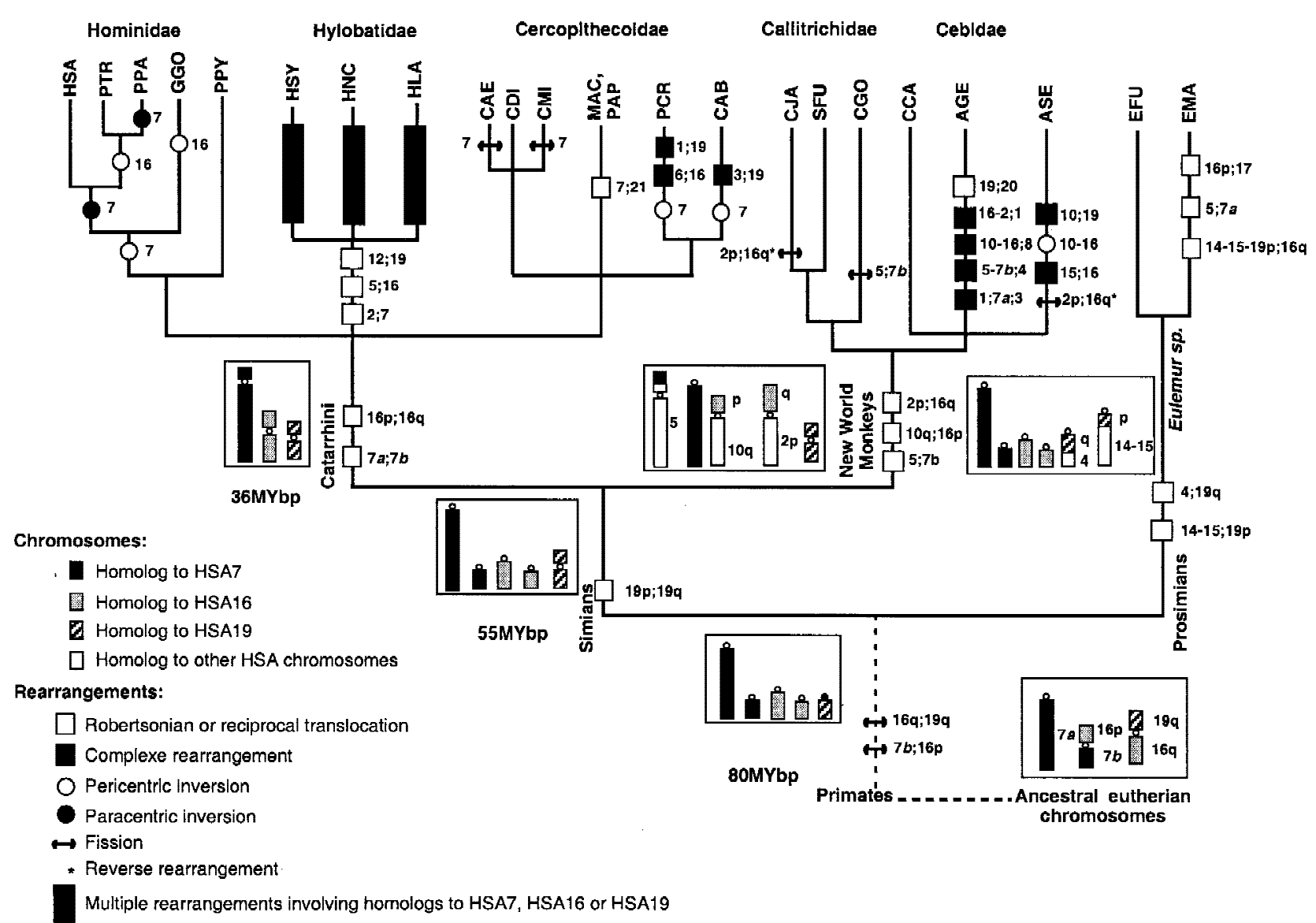

Figure 4 Phylogenetic tree of primates established from banding (PPA, CAE, CMI, PCR, CAB, SFU, and CGO; see references in Dutrillaux et al. 1986) and Zoo-FISH (others species) data. Numbers refer to human homologous chromosomes. Ancestral forms of HSA7, HSA16, and HSA19 homologs are boxed. Only rearrangements involving at least one homolog to HSA7, HSA16, or HSA19 are indicated. Semicolons separate chromosomes involved in a same rearrangement and hyphens indicate pre-existing syntenies. Approximate branch-

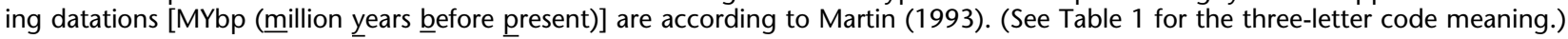

1979b). During evolution, this chromosome either remained unchanged as in the white-throated capuchin and the marmoset (Richard et al. 1996; Sherlock et al. 1996) or was further rearranged as in the black-handed spider and red howler monkeys (Morescalchi et al. 1997; Consigliere et al. 1996, respectively). The ancestral simian acrocentric homologous to HSA16q underwent a Robertsonian translocation with the HSA2p homolog in a common ancestor to New World monkeys (Dutrillaux 1988). Further rearrangements of this ancestral chromosome occurred such as translocations in spider monkeys (Morescalchi et al. 1997) and apparently independent reverse fissions in the marmoset and the red howler monkey (Consigliere et al. 1996; Sherlock et al. 1996). Chromosome $7 a$ remained free except in the black-handed spider monkey. The ancestral simian acrocentric $7 b$ underwent a translocation with the HSA5 homolog forming a submetacentric. Then, this chromosome underwent a fission in the Goeldi's monkey (Dutrillaux et al. 1988) or a translo- cation in the black-handed spider monkey (Morescalchi et al. 1997).

Finally, among Catarrhines, the syntenies HSA16p-HSA16q and 7a-7b exist in all the studied species. Except for heterochromatin variations, a metacentric chromosome similar to HSA16 is observed in many species. It is proposed to be ancestral for Catarrhines. This chromosome was formed before the divergence between Old World monkeys and apes and remained fairly stable. A Robertsonian translocation formed a submetacentric homologous to HSA7 considered as the ancestral form for all Catarrhines. Then, it underwent a translocation with the HSA21 homolog in macaque and baboon ancestrors, forming their chromosome 2 . It remained free in other Old World monkeys and underwent various fissions in guenons and inversions in leaf monkeys (Muleris et al. 1986). In gibbons, syntenies HSA2-HSA7, HSA5-HSA16, and HSA12-HSA19 were observed in several species (Jauch et al. 1992; Koehler et al. 1995; Müller et al. 1998), suggesting they 
were formed by translocations that occurred in common ancestors of this family. In great apes and man, the homolog to HSA7 remained free and underwent a pericentric inversion after the orangutan divergence, a paracentric inversion after the gorilla divergence, and another paracentric inversion in the bonobo. Thus, only the chimpanzee and man share the same chromosome (Dutrillaux 1979a).

The rearrangements involving homologs to HSA7 during evolution of primates are quite informative. Considered together with rearrangements involving HSA16 and HSA19 homologs, they allowed us to propose many branchings. These branchings, however, remain insufficient for reconstructing a complete phylogenetic tree. It must be pointed out that the dichotomic tree of Figure 4 is an oversimplification of the events that have occurred. When more species and chromosomes will be studied by chromosome painting, it should appear that a network is more likely than a dichotomic evolution, as suggested by chromosome banding studies.

\section{METHODS}

\section{Studied Species}

Cultures were developed from fibroblasts conserved in liquid nitrogen in our cell repository. The 11 species analyzed in this study belong to 7 orders of placental mammals. To reconstruct chromosome changes, published data were also considered, which allowed us to compare chromosomes from species belonging to 11 orders. Latin names, English names, and abbreviations of the studied species considered are described in Table 1.

\section{Chromosome Banding}

Chromosome banding techniques and comparisons were made after fibroblast cultures, according to our usual methods (Dutrillaux and Couturier 1981).

\section{Zoo-FISH}

In situ hybridization using whole human chromosome 7, 16, or 19 probes (Cambio-Biosys, Compiègne, France) were performed on metaphases of the studied species. Probes were revealed in green by indirect detection with an anti-biotin antibody followed by an FITC-conjugated anti-goat antibody. Chromosomes were counterstained in blue with DAPI and identified with a computer generated reverse DAPI banding. For some species, G banding was revealed in red simultaneously by an indirect detection of the 5-bromodeoxyuridine incorporated to chromosomes during the last $10 \mathrm{hr}$ of culture (Richard et al. 1996). Observations were performed under an epifluorescence microscope (Microphot-FXA, Nikon, Japan) and images were captured using a cooled CCD camera and a software (Quips-Smart, Vysis, Downers Grove, IL).

\section{ACKNOWLEDGMENTS}

We are grateful to Pr. Yves Rumpler and the veterinary surgeons from the Museum National d'Histoire Naturelle de Paris for the obtention of tissue specimens; and we thank M.F. La- vigne for secretarial assistance and $\mathrm{K}$. Truong for reading the manuscript.

The publication costs of this article were defrayed in part by payment of page charges. This article must therefore be hereby marked "advertisement" in accordance with 18 USC section 1734 solely to indicate this fact.

\section{REFERENCES}

Apiou, F., Y. Rumpler, S. Warter, A. Vezuli, and B. Dutrillaux. 1996. Demonstration of homoeologies between human and lemur chromosomes by chromosome painting. Cytogenet. Cell Genet. 72: $50-52$.

Bielec, P.E., D.S. Gallagher, J.E. Womack, and D.L. Busbee. 1998. Homologies between human and dolphin chromosomes detected by heterologous chromosome painting. Cytogenet. Cell Genet. 81: $18-25$.

Burkin, D.J., F. Yang, T.E. Broad, J. Wienberg, D.F. Hill, and M.A. Ferguson-Smith. 1997. Use of the Indian Muntjac idiogram to align conserved chromosomal segments in sheep and human genomes by chromosome painting. Genomics 46: 143-147.

Chowdhary, B.P., P. Raudsepp, L. Frönicke, and H. Scherthan. 1998. Emerging patterns of comparative genome organization in some mammalian species by Zoo-FISH. Genome Res. 8: 577-589.

Consigliere, S., R. Stanyon, U. Koehler, G. Agoramoorthy, and J. Wienberg. 1996. Chromosome painting defines genomic rearrangements between red howler monkey subspecies. Chrom. Res. 4: $264-270$.

Dixkens, C., C. Klett, J. Bruch, A. Kollak, O.L. Serov, N. Zhdanova, W. Vogel, and H. Hameister. 1998. ZOO-FISH analysis in insectivores: "Evolution extols the virtue of the status quo." Cytogenet. Cell Genet. 80: 61-67.

Dutrillaux, B. 1975. Sur la nature et l'origine des chromosomes humains. Monographie des Annales de Génétique. Expansion Scientifique Française, Paris, France.

-1979a. Chromosomal evolution in primates: Tentative phylogeny from Microcebus murinus (Prosimian) to man. Hum. Genet. 48: 251-314.

- 1979b. Very large analogy of chromosome banding between Cebus capucinus (Platyrrhini) and man. Cytogenet. Cell Genet. 24: 84-94.

- 1988. New interpretation of the presumed common ancestral karyotype of platyrrhine monkeys. Cytogenet. Cell Genet. 50: $226-229$.

Dutrillaux, B. and J. Couturier. 1981. La pratique de l'analyse chromosomique. Masson, Paris.

-1983. The ancestral karyotype of carnivora: Comparison with that of platyrrhine monkeys. Cytogenet. Cell Genet. 35: 200-208.

Dutrillaux, B., E. Viegas-Péquignot, and J. Couturier. 1980. Très grande analogie de marquage chromosomique entre le lapin (Oryctolagus cuniculus) et les primates, dont l'homme. Ann. Génét. 23: $22-25$.

Dutrillaux, B., J. Couturier, E. Viegas-Péquignot, and M. Muleris. 1982. Cytogenetic aspects of Primates evolution. Human genetics, part A: The unfolding genome, pp. 183-194. Alan R. Liss, Inc., New York, NY.

Dutrillaux, B., J. Couturier, M. Muleris, Y. Rumpler, and E. Viegas-Péquignot. 1986. Relations chromosomiques entre sous-ordres et infra-ordres, et schéma évolutif général des Primates. Mammalia 50: 108-121.

Dutrillaux, B., M. Lombard, J.B. Carrol, and R.D. Martin. 1988. Chromosomal affinities of Callimico goeldii (Platyrrhini) and characterization of a Y-autosome translocation in the male. Folia Primatol. 50: 238-244.

Frönicke, L., B.P. Chowdhary, H. Scherthan, and I. Gustavsson. 1996. A comparative map of the porcine and human genome demonstrates ZOO-FISH and gene mapping-based chromosomal homologies. Mamm. Genome 7: 285-290.

Frönicke, L., J. Müller-Navia, K. Romanakis, and H. Scherthan. 1997. Chromosomal homeologies between human, harbor seal (Phoca vitulina) and the putative ancestral carnivore karyotype revealed 
by ZOO-FISH. Chromosoma 106: 108-113.

Guilly, M.N., P. Fouchet, P. de Chamisso, A. Schmitz, and B. Dutrillaux. 1999. Comparative karyotype of rat and mouse using bidirectional chromosome painting. Chrom. Res. 7: 213-221.

Hameister, H., Ch. Klett, J. Bruch, Ch. Dixkens, W. Vogel, and K. Christensen. 1997. ZOO-FISH analysis: The American mink (Mustela vison) closely resembles the cat karyotype. Chrom. Res. 5: 5-11.

Hayes, H. 1995. Chromosome painting with human chromosome-specific DNA libraries reveals the extent and distribution of conserved segments in bovine chromosomes. Cytogenet. Cell Genet. 71: 168-174.

Jauch, A., J. Wienberg, R. Stanyon, N. Arnold, S. Tofanelli, T. Ishida, and T. Cremer. 1992. Reconstruction of genomic rearrangements in great apes and gibbons by chromosome painting. Proc. Natl. Acad. Sci. 89: 8611-8615.

Koehler, U., F. Bigoni, J. Wienberg, and R. Stanyon. 1995. Genomic reorganization in the Concolor gibbon (Hylobates concolor) revealed by chromosome painting. Genomics 30: 287-292.

Martin, R.D. 1993. Primate origins: Plugging the gaps. Nature 363: 223-234.

Morescalchi, M.A., W. Schempp, S. Consigliere, F. Bigoni, J. Wienberg, and R. Stanyon. 1997. Mapping chromosomal homology between humans and the black-handed spider monkey by fluorescence in situ hybridization. Chrom. Res. 5: 527-536.

Muleris, M., M. Paravatou-Petsota, and B. Dutrillaux. 1984. Diagrammatic representation for chromosomal mutagenesis studies II. Radiation-induced rearrangements in Macaca fascicularis. Mutat. Res. 126: 93-103.

Muleris, M., J. Couturier, and B. Dutrillaux. 1986. Phylogénie chromosomique des Cercopithecoidea. Mammalia 50: 38-52.

Müller, S., P.C.M. O'Brien, M.A. Ferguson-Smith, and J. Wienberg. 1997. Reciprocal chromosome painting between human and prosimians (Eulemur macaco macaco and E. fulvus mayottensis). Cytogenet. Cell Genet. 78: 260-271.

. 1998. Cross-species colour segmenting: A novel tool in human karyotype analysis. Cytometry 33: 445-452.

Nash, W.G., J. Wienberg, M.A. Ferguson-Smith, J.C. Menninger, and S.J. O'Brien. 1998. Comparative genomics: Tracking chromosome evolution in the family Ursidae using reciprocal chromosome painting. Cytogenet. Cell Genet. 83: 182-192.
Novacek, M.J. 1992. Mammalian phylogeny : Shaking the tree. Nature 356: 121-125.

Petit, D., J. Couturier, E. Viegas-Péquignot, M. Lombard, and B. Dutrillaux. 1984. Très grande similitude entre le caryotype ancestral des écureuils (rongeurs) et celui des primates et des carnivores. Ann. Génét. 27: 201-212.

Raudsepp, T., L. Frönicke, H. Scherthan, I. Gustavsson, and B.P. Chowdhary. 1996. ZOO-FISH delineates conserved chromosomal segments in horse and man. Chrom. Res. 4: 218-225.

Rettenberger, G., C. Klett, U. Zechner, J. Kunz, W. Vogel, and H. Hameister. 1995. Visualization of the conservation of syntheny between humans and pigs by heterologous chromosomal painting. Genomics 26: 372-378.

Richard, F., M. Lombard, and B. Dutrillaux. 1996. ZOO-FISH suggests a complete homology between human and capuchin monkey (Platyrrhini) euchromatin. Genomics 36: 417-423.

Scalzi, J.M. and J.C. Hozier. 1998. Comparative genome mapping: Mouse and rat homologies revealed by fluorescence in situ. Genomics 47: 44-51.

Sherlock, J.K., D.K. Griffin, J.D.A. Delhanty, and J.M. Parrington. 1996. Homologies between human and marmoset (Callithrix jacchus) chromosomes revealed by comparative chromosome painting. Genomics 33: 214-219.

Volleth, M., C. Klett, A. Kollak, C. Dixkens, Y. Winter, W. Just, W. Vogel, and H. Hameister. 1999. ZOO-FISH analysis in a species of the order Chiroptera: Glossophaga soricina (Phyllostomidae). Chrom. Res. 7: 57-64.

Wienberg, J., R. Stanyon, A. Jauch, and T. Cremer. 1992. Homologies in human and Macaca fuscata chromosomes revealed by in situ suppression hybridization with human chromosome specific DNA libraries. Chromosoma 101: 265-270.

Wienberg, J., R. Stanyon, W.G. Nash, P.C.M. O'Brien, F. Yang, S.J. O'Brien, and M.A. Ferguson-Smith. 1997. Conservation of human vs. feline genome organization revealed by reciprocal chromosome painting. Cytogenet. Cell Genet. 77: 211-217.

Yang, F., S. Müller, R. Just, M.A. Ferguson-Smith, and J. Wienberg. 1997. Comparative chromosome painting in mammals: Human and the Indian Muntjac (Muntiacus muntjak vaginalis). Genomics 39: 396-401.

Received December 7, 1999 ; accepted in revised form March 9, 2000.
Genome Research www.genome.org 


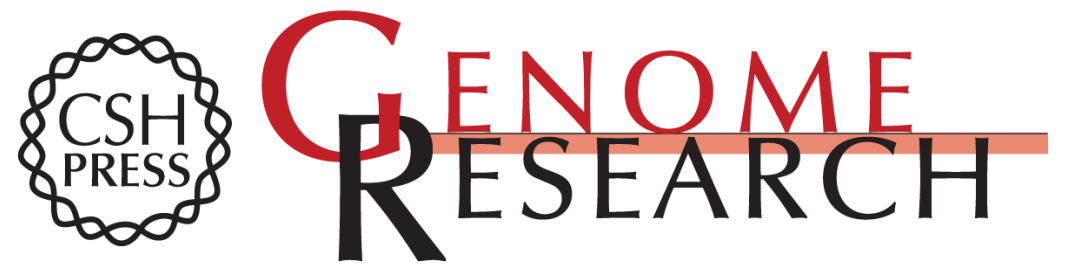

\section{Phylogenetic Origin of Human Chromosomes 7, 16, and 19 and their Homologs in Placental Mammals}

Florence Richard, Martine Lombard and Bernard Dutrillaux

Genome Res. 2000 10: 644-651

Access the most recent version at doi:10.1101/gr.10.5.644

References This article cites 31 articles, 2 of which can be accessed free at:

http://genome.cshlp.org/content/10/5/644.full.html\#ref-list-1

\section{License}

Email Alerting Receive free email alerts when new articles cite this article - sign up in the box at the Service top right corner of the article or click here.

\section{Affordable, Accurate Sequencing.}

